\title{
Atrial Fibrillation after Cardiac Surgery-To Infinity and Beyond!
}

\author{
Oana Maria Cole 1,2 \\ ${ }^{1}$ Liverpool Centre for Cardiovascular Science, University of Liverpool, \\ Liverpool, United Kingdom \\ ${ }^{2}$ Heart and Chest Hospital, Liverpool, United Kingdom
}

Thromb Haemost 2021;121:1391-1393.

\author{
Address for correspondence Oana Maria Cole, MBBS, FRCA, EDIC, \\ Liverpool Heart and Chest Hospital NHS Foundation Trust - \\ Anaesthesia, Thomas Drive Liverpool, Merseyside L14 3PE, United \\ Kingdom (e-mail: Oana.Cole@lhch.nhs.uk).
}

"It isn't that they can't see the solution. It is that they can't see the problem."

G.K. Chesterton, “The Scandal of Father Brown” (1935)

New-onset atrial fibrillation (AF) is common after cardiac surgery, with an incidence of 30 to $50 \% .^{1-3}$ Patients developing de novo AF after cardiac surgery (AFACS) have a higher risk of developing persistent/long-term AF in the community. ${ }^{4}$ An episode of AFACS, even if terminated prior to discharge from hospital, is associated with an increased longterm risk of embolic stroke ${ }^{5}$ and higher 10-year all-cause mortality. ${ }^{6}$ Considering this, it is then perhaps not surprising that AF has been named as one of the top 10 research priorities for cardiovascular surgery. ${ }^{7}$

\section{Pathophysiology of Atrial Fibrillation after Cardiac Surgery}

Accurate risk quantification for AFACS has been one of the holy grails of research in cardiothoracic perioperative medicine. The quest for risk factors and models has been relatively unrewarding so far, despite a lot having been published. A recent PubMed search using the key words "atrial fibrillation" and "cardiac surgery" rendered 7,716 publications between 1957 and 2021, with 2,449 papers mentioning or entirely focusing on risk prediction for AFACS.

Even though little detail is known about the precise molecular mechanisms underlying the onset and perpetuation of AFACS, recent evidence points to proarrhythmic mechanisms acting on a background of structural remodeling. Disease- and surgery-related triggers accelerate or even tip the risk balance toward AF in patients who are already at risk, due to age, gender, and comorbidities; hence, the importance of proper AF characterization as part of clinical evaluation. ${ }^{8}$ Risk factors are also dynamic in nature, changing with age and incident comorbidities ${ }^{9}$ (-Fig. 1).

A remodeled atrial tissue, with structural changes, increased wall strain, and increased chamber dimensions, is much more sensitive to the effects of proinflammatory cytokines, reactive oxygen species, and increased adrenergic drive. ${ }^{10}$ Surgical trauma and ischemia and reperfusion from the use of cardioplegia and cardiopulmonary bypass lead to oxidative stress and production of proinflammatory molecules, resulting in endothelial activation. Systemic inflammation and oxidative stress have been shown to be associated with increased incidence of AFACS. ${ }^{10,11}$ Details of the conceptual model underpinning this are beyond the scope of this editorial note. Nevertheless, it is worth pointing out that structural remodeling of the atrial tissue, together with connexin and ion-channel remodeling, is among the possible mechanisms proposed. ${ }^{12}$

\section{Risk Models for Atrial Fibrillation after Cardiac Surgery}

There have been several AFACS-predictive models published, the most notable of which are Postoperative $A F,{ }^{13}$ Atrial Fibrillation Risk Index, ${ }^{14}$ and even a stroke prediction score ${ }^{15}$ as a prediction tool for risk of new-onset AFACS in the setting of cardiopulmonary bypass grafting. ${ }^{16}$ However, the predictive ability of these scores has not been supported by external validation, with the best area under the receiver operator characteristic curve of 0.68 (95\% confidence interval: 0.67-0.69), ${ }^{17}$ typical of clinical-factor-based risk scores.

Aristotle famously said that "the whole is something besides the parts" (Aristotle, Metaphysics, translated by W. D. Ross). It is likely that none of these scores performed well because we have been asking the wrong question. Instead of a static, almost reductionist approach, we should perhaps consider the alternative view of a dynamic risk trajectory for AFACS. It is a well-known fact that the pathogenesis of AFACS is heterogeneous, with acute changes in physiology

(C) 2021. Thieme. All rights reserved. Georg Thieme Verlag KG,

Rüdigerstraße 14,

70469 Stuttgart, Germany
DOI https://doi.org/ 10.1055/a-1506-8744. ISSN 0340-6245.

accepted

May 10, 2021

published online

May 11, 2021 


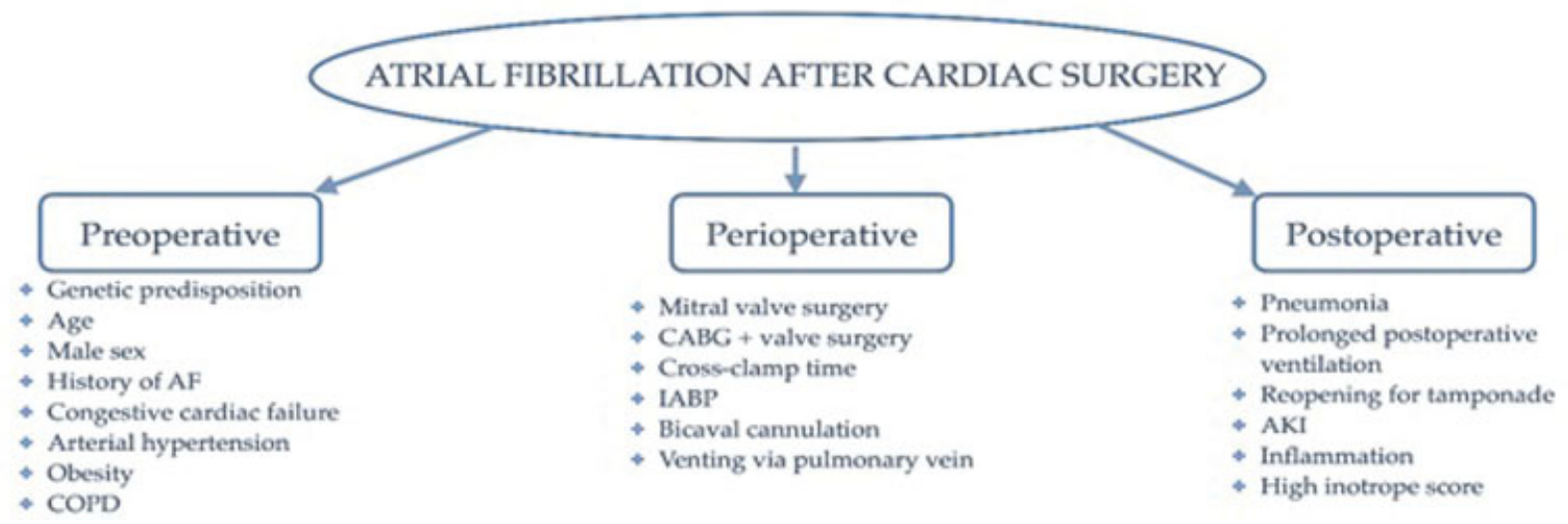

Fig. 1 Risk factors associated with new-onset AF after cardiac surgery (AFACS) highlight the main risk factors associated with AFACS. AF, atrial fibrillation.

Table 1 Atrial fibrillation after cardiac surgery-best validated prediction scores

\begin{tabular}{|l|l|l|l|}
\hline Authors, year & Type of surgery & $\begin{array}{l}\text { Number } \\
\text { of patients }\end{array}$ & $\begin{array}{l}\text { Area under ROC in external } \\
\text { validation model }^{17}\end{array}$ \\
\hline El-Chami et al, 2012 & CABG, single center & 18,517 & $0.56 ; 95 \% \mathrm{Cl}: 0.52-0.60$ \\
\hline $\begin{array}{l}\text { Chua et al, 2013 (using CHADS2 and } \\
\text { CHA2DS2-VASc scores) }\end{array}$ & $\begin{array}{l}\text { CABG, valve, CABG + valve; } \\
\text { single center }\end{array}$ & 277 & $0.59 ; 95 \% \mathrm{Cl}: 0.55-0.62$ \\
\hline Mariscalco et al, 2014 & $\begin{array}{l}\text { CABG, valve, CABG + valve } \\
\text { surgery; multicenter }\end{array}$ & 17,262 & $0.65 ; 95 \% \mathrm{Cl}: 0.62-0.68$ \\
\hline
\end{tabular}

Abbreviations: CABG, coronary artery bypass grafting; $\mathrm{Cl}$, confidence interval; ROC, receiver operating characteristic curve.

compounding the preoperative comorbidities and genetic predisposition. ${ }^{1,18,19}$ We may then make the argument for a Bayesian approach to risk evaluation for such a complex pathological entity.

Effective acute prophylactic options for AFACS are available $^{20-22}$ and validated in guidelines. ${ }^{23}$ However, these interventions are not effective in all patients, and some have a high risk of adverse effects. Therefore, it is crucial to be able to identify the individuals at high risk of developing AFACS, as well as to track the risk of developing AFACS throughout their immediate postoperative course as the risk is dynamic and ever-changing in response to the environment and stressors patients are exposed to. The risk of de novo AFACS is dynamic, continuously varying with changes in perioperative physiology.

Tissue samples taken from patients at the end or at the start of surgery provide useful insights into the preexisting substrate and the surgery-induced substrate for the development of AF. However, this approach is obviously not an easy, feasible option for the real-world patients.

In this issue of the journal, the article by Hofer et $\mathrm{al}^{24}$ fills an important gap-it quantifies the degree of cardiomyocyte strain as expressed by the levels of circulating atrial natriuretic peptide (ANP) contributing to AFACS. ANP is released in response to atrial-wall stretch. An analysis of patients in the sixth examination cycle of the Framingham Offspring Study showed that high levels of ANP are associ- ated with increased risk of AF in the community. ${ }^{25}$ The focus in the Hofer et al article is apparently on the ANP. However, as the authors astutely highlight in their analysis, it is also the combined levels of ANP and B-type natriuretic peptide which point to a higher risk of AFACS ${ }^{24}$ (-Table 1).

\section{Future Perspectives}

Investigations into risk modeling approaches for this most common type of secondary AF will still continue. Despite the enthusiasm for biomarker-based scores, the challenge is that many biomarkers are nonspecific, being predictive of outcomes beyond what the scores were proposed for, ${ }^{26}$ indicative of a sick patient or a sick heart. ${ }^{27}$

As we enter the third decade of the 21 st century, we, as a medical community, are becoming increasingly aware of the possibilities afforded by data science and artificial intelligence. Integrating the ever-expanding information available, sifting through the risk categories and defining the risk trajectory for AFACS is becoming more of a challenge for a single individual and more appropriate for a clinical decision support system based on machine learning, especially given new advances in the latter for the prediction of $\mathrm{AF}$ and stroke. $^{28}$

Conflict of Interest

None declared. 


\section{References}

1 Lomivorotov VV, Efremov SM, Pokushalov EA, Karaskov AM. Newonset atrial fibrillation after cardiac surgery: pathophysiology, prophylaxis, and treatment. J Cardiothorac Vasc Anesth 2016;30 (01):200-216

2 Greenberg JW, Lancaster TS, Schuessler RB, Melby SJ. Postoperative atrial fibrillation following cardiac surgery: a persistent complication. Eur J Cardiothorac Surg 2017;52(04):665-672

3 Gillinov AM, Bagiella E, Moskowitz AJ, et al; CTSN. Rate control versus rhythm control for atrial fibrillation after cardiac surgery. N Engl J Med 2016;374(20):1911-1921

4 Melduni RM, Schaff HV, Bailey KR, et al. Implications of new-onset atrial fibrillation after cardiac surgery on long-term prognosis: a community-based study. Am Heart J 2015;170(04):659-668

5 Lowres N, Mulcahy G, Jin K, Gallagher R, Neubeck L, Freedman B. Incidence of postoperative atrial fibrillation recurrence in patients discharged in sinus rhythm after cardiac surgery: a systematic review and meta-analysis. Interact Cardiovasc Thorac Surg 2018;26(03):504-511

6 Phan K, Ha HSK, Phan S, Medi C, Thomas SP, Yan TD. New-onset atrial fibrillation following coronary bypass surgery predicts long-term mortality: a systematic review and meta-analysis. Eur J Cardiothorac Surg 2015;48(06):817-824

7 Lai FY, Abbasciano RG, Tabberer B, Kumar T, Murphy GJSteering Group of the James Lind Alliance Heart Surgery Priority Setting Partnership. Identifying research priorities in cardiac surgery: a report from the James Lind Alliance Priority Setting Partnership in adult heart surgery. BMJ Open 2020;10(09):e038001

8 Potpara TS, Lip GYH, Blomstrom-Lundqvist C, et al. The 4S-AF scheme (Stroke Risk; Symptoms; Severity of Burden; Substrate): a novel approach to in-depth characterization (rather than classification) of atrial fibrillation. Thromb Haemost 2021;121(03):270-278

9 Chao TF, Liao JN, Tuan TC, et al. Incident co-morbidities in patients with atrial fibrillation initially with a CHA2DS2-VASc score of 0 (males) or 1 (females): implications for reassessment of stroke risk in initially 'low-risk' patients. Thromb Haemost 2019;119 (07):1162-1170

10 Zakkar M, Ascione R, James AF, Angelini GD, Suleiman MS. Inflammation, oxidative stress and postoperative atrial fibrillation in cardiac surgery. Pharmacol Ther 2015;154:13-20

11 Ishii Y, Schuessler RB, Gaynor SL, Hames K, Damiano RJ Jr. Postoperative atrial fibrillation: the role of the inflammatory response. J Thorac Cardiovasc Surg 2017;153(06):1357-1365

12 Dobrev D, Aguilar M, Heijman J, Guichard JB, Nattel S. Postoperative atrial fibrillation: mechanisms, manifestations and management. Nat Rev Cardiol 2019;16(07):417-436

13 Mariscalco G, Biancari F, Zanobini M, et al. Bedside tool for predicting the risk of postoperative atrial fibrillation after cardiac surgery: the POAF score. J Am Heart Assoc 2014;3(02):e000752

14 El-Chami MF, Kilgo PD, Elfstrom KM, et al. Prediction of new onset atrial fibrillation after cardiac revascularization surgery. Am J Cardiol 2012;110(05):649-654

15 Lip GYH, Nieuwlaat R, Pisters R, Lane DA, Crijns HJ. Refining clinical risk stratification for predicting stroke and thromboembolism in atrial fibrillation using a novel risk factor-based ap- proach: the euro heart survey on atrial fibrillation. Chest 2010; 137(02):263-272

16 Chua SK, Shyu KG, Lu MJ, et al. Clinical utility of CHADS2 and CHA2DS2-VASc scoring systems for predicting postoperative atrial fibrillation after cardiac surgery. J Thorac Cardiovasc Surg 2013;146(04):919.e1-926.e1

17 Cameron MJ, Tran DTT, Abboud J, Newton EK, Rashidian H, Dupuis JY. Prospective external validation of three preoperative risk scores for prediction of new onset atrial fibrillation after cardiac surgery. Anesth Analg 2018;126(01):33-38

18 Maesen B, Nijs J, Maessen J, Allessie M, Schotten U. Post-operative atrial fibrillation: a maze of mechanisms. Europace 2012;14(02): 159-174

19 Kertai MD, Li YJ, Ji Y, et al; Duke Perioperative Genetics and Safety Outcomes (PEGASUS) Investigative Team. Genome-wide association study of new-onset atrial fibrillation after coronary artery bypass grafting surgery. Am Heart J 2015;170(03):580-90.e28

20 Burgess DC, Kilborn MJ, Keech AC. Interventions for prevention of post-operative atrial fibrillation and its complications after cardiac surgery: a meta-analysis. Eur Heart J 2006;27(23): 2846-2857

21 Crystal E, Connolly SJ, Sleik K, Ginger TJ, Yusuf S. Interventions on prevention of postoperative atrial fibrillation in patients undergoing heart surgery: a meta-analysis. Circulation 2002;106(01): 75-80

22 Eridon JM, Ferguson MK. Prevention of postoperative atrial fibrillation after adult cardiac surgery. In: Lonchyna VA, ed. Difficult Decisions in Cardiothoracic Critical Care Surgery. Difficult Decisions in Surgery: An Evidence-Based Approach. Cham: Springer International Publishing; 2019:187-98

23 Muehlschlegel JD, Burrage PS, Ngai JY, et al. Society of Cardiovascular Anesthesiologists/European Association of Cardiothoracic Anaesthetists practice advisory for the management of perioperative atrial fibrillation in patients undergoing cardiac surgery. Anesth Analg 2019;128(01):33-42

24 Hofer F, Hammer A, Steininger M, et al. The prognostic potential of atrial natriuretic peptide on the development of postoperative atrial fibrillation after cardiac surgery. Thromb Haemost 2021; 121(11):1523-1529

25 Wang TJ, Larson MG, Levy D, et al. Plasma natriuretic peptide levels and the risk of cardiovascular events and death. N Engl J Med 2004;350(07):655-663

26 Camelo-Castillo A, Rivera-Caravaca JM, Marín F, Vicente V, Lip GYH, Roldán V. Predicting adverse events beyond stroke and bleeding with the $\mathrm{ABC}$-stroke and $\mathrm{ABC}$-bleeding scores in patients with atrial fibrillation: the Murcia AF Project. Thromb Haemost 2020;120(08):1200-1207

27 Esteve-Pastor MA, Roldán V, Rivera-Caravaca JM, Ramírez-Macías I, Lip GYH, Marín F. The use of biomarkers in clinical management guidelines: a critical appraisal. Thromb Haemost 2019;119(12): 1901-1919

28 Lip GY, Genaidy A, Tran G, Marroquin P, Estes C, Sloop S. Improving stroke risk prediction in the general population: Common clinical rules, a new multimorbid index and machine learning based algorithms. Thromb Haemost 2021. Doi: 10.1055/a-1467-2993 